\title{
Chapter 8 \\ Connecting Environmental Changes, Migration Causality, and Transnational \\ Practices. Insights from the Moroccan Diaspora in Belgium
}

In this chapter we turn to relevant findings arising from fieldwork conducted in Belgium in the context of the MIGRADAPT project. Although the Moroccan case study that forms the core of this book must be interpreted independently from the empirical data provided in this chapter (and vice versa), both case studies hinge on the same theoretical framework and are, as such, inherently complementary and connected, although not meant to be directly comparative.

As set out in Chap. 4, the MIGRADAPT project seeks to explore how perceptions of environmental changes can impact the migration aspirations, trajectories, and realities of selected diaspora communities living in Belgium (specifically Moroccan, Senegalese, and Congolese migrants) and to appraise the conditions under which migrants may, in turn, contribute to supporting the adaptation and resilience of their communities of origin (cf. Chap. 4). This chapter adds value to the empirical evidence contained in previous chapters by presenting the ancillary perspective of Moroccan migrants living in Belgium regarding matters that form the red thread of this book, namely: (perceived) environmental changes, migration aspirations, adaptation strategies, and cultures of migration. In doing so, we further flesh out the similarities and distinctions that can be made between mobile and immobile Moroccan populations, contributing to a better understanding of transnational practices in the context of environmental change.

Most empirical studies conclude that migration resulting at least in part from environmental changes will remain within the borders of that country, i.e., internal migration. We take a different approach by interviewing international migrants from Morocco in Belgium. Although studies exist to examine migration between Morocco and Europe (Collyer 2007; Berriane et al. 2015) - including between Morocco and Belgium (Bousetta and Martiniello 2003; Ouali 2004; Martiniello and Rea 2013; Zickgraf 2014; Timmerman et al. 2017) - only a few used a transnational approach focusing on communities of origin and members of the diaspora, and none of them specifically investigate the potential interactions between environmental factors and migration journeys to Belgium or the impact of environmental perceptions on transnational practices between Belgium and Morocco. 
In doing so, one of this chapter's main objectives is to interrogate the environment-migration nexus through a perspective that reconciles the study of migration drivers with that of migration impacts. Today, scholars, policymakers, development practitioners, and the general public recognise that the impacts of disasters, climate change, and other environmental disruptions are shaping human mobility (TGOFS 2011; Kumari Rigaud et al. 2018) and immobility (Black and Collyer 2014; Zickgraf 2018; Ayeb-Karlsson et al. 2018). While acknowledging multi-causality as inherent to any migration decision, environmental disruptions are increasingly identified and presented as primary migration and displacement drivers. For example, $74.5 \%$ of new internal displacements that occurred in 2019 were triggered by disasters (mainly weather-related) rather than by conflict and violence (IDMC 2020). While sudden events like flooding are forcing people from their homes, slow-onset changes induced by climate change are also moulding human migration patterns and dynamics. Sea-level rise, soil salinization, coastal erosion, drought, and climatic variability are affecting the physical inhabitability of affected communities while also making it harder to sustain local livelihoods, especially when those livelihoods are natural-resource dependent. As livelihoods degrade, many people are on the move in search of better opportunities.

Identifying the role of environmental and climatic changes in driving human mobility (migration, displacement, immobility) is essential to progressing scientifically and in the design and implementation of effective policies treating the environment-migration nexus. However, addressing the issue of causality alone does not adequately capture the many links between climate change (and other environmental changes) and human mobility. A less studied, but equally important, task is to understand the outcomes and the impacts of human mobility. The relationship between environment and migration does not end with the out-migration of an individual or household: migration can impact environmental change in a variety of ways. Migration can affect environmental conditions in the host area, through increased pressure on natural resources, for example. Migration also affects the community of origin via the (potential) reduced pressure on natural resources, as well as with financial and social remittances that can increase the adaptive capacity of households and communities.

These two foci of study, causality and impacts of migration, for the most part have been treated separately from one another. In this contribution, we bridge the fields by addressing how causality of migration affects the subsequent impacts of migration in communities of origin. Importantly, we acknowledge that any form or motivation of migration (even if environmental factors are not a stated primary driver) can impact communities of origin under environmental duress, and so, in addition to analysing the role of environment in shaping the migration journeys of participants, we analyse how perceptions of environmental changes ${ }^{1}$ in the community of origin translate into transnational practices. We then assess how transnational practices affect environmental resilience in communities of origin.

\footnotetext{
${ }^{1}$ We refer here to 'environmental changes' as a broad category that encompasses climate change.
} 
This chapter starts by reviewing the literature on environmental changes and migration, primarily focusing on how migration acts as a potential adaptation strategy, rather than the failure to adapt. It then delves into empirical findings in three aspects: migrants' perceptions of environmental changes in Morocco, their motivations for migration, and their ensuing transnational practices between Belgium and Morocco. Finally, it analyses how these three aspects link to impact the environmental resilience of communities of origin.

\subsection{Emergence of the Migration-as-Adaptation Discourse}

Although some early studies tackled the impact of migration on environmental conditions in areas of destination, e.g., refugee camps in Somalia (Young 1985), to date the vast majority of scholarship on the environment-migration nexus focuses on issues of causality. This holds particularly true for academic and grey literature studies of climate change and how it drives out-migration from affected areas. Indeed, how climate change drives (or will drive) migration and displacement forms the heart of public and political discussions on climate change, with migrants becoming the 'human face' of global warming (Gemenne 2011). In the early stages of attention to these issues, migration was portrayed rather negatively as an international humanitarian and security threat should climate action fail to take place, resulting in terms such as 'climate refugees'.

However, already in the early 1990s, migration scholars refuted these largely negative, and simplistic, depictions. This well-documented divide eventually produced an alternate body of work based mostly on empirical, qualitative case studies (Suhrke 1993; Morrissey 2012; Gemenne 2018). Evidence suggests two main findings: first, human mobility linked to environmental change (including but not exclusive to climate change impacts) is primarily internal, and second, mobility is multi-causal. The former point challenges public and civil society discourses in the Global North that expect mass 'waves' of 'climate refugees' to arrive in places like Europe. The latter demonstrates that attributing migration singularly to climate change - and, for that matter, isolating any one driver of migration - ignores the complexity of migration in that it results from a combination of social, political, economic, environmental, and demographic factors (TGOFS 2011; Piguet and Lackzo 2014; McLeman and Gemenne 2018). Moreover, climate change acts as a threat multiplier, potentially influencing all these drivers. Outside of situations of direct sudden-onset disaster displacement, in fact, people are more likely to cite the impacts of environmental changes (poverty, decreased agricultural productivity, rising food insecurity, etc.) as motivating their migrations rather than explicitly citing the changes themselves (Suhrke 1993; Hugo 1996; Nguyen and Wodon 2014; Kumari Rigaud et al. 2018). Migration decisions can also be derived from more individual characteristics and socio-demographic variables such as one's education level, type of activity, gender, and age (Henry et al. 2003, 2004; Van der Land and Hummel 2013). 
One of the most significant outcomes of this empirical pushback is the migrationas-adaptation discourse. Although it largely emerged in the past decade, it builds on various bodies of work in environmental community research, development studies, and 'mainstream' migration scholarship, including the Sustainable Livelihoods Approach (Brocklesby and Fisher 2003) and the new economics of labour migration (Stark and Bloom 1985; Stark 2005; Taylor 1999; cf. Chap. 2). Migration is seen as one strategy - among others - to secure or diversify or both the livelihoods of a given individual, household, or community, especially in those that are heavily reliant upon natural resources (Kniveton et al. 2008; Gemenne 2010). This refuted any universal categorization of human mobility caused (in part) by climate and other environmental changes as a last resort. Additionally, it highlighted not just the choice to leave, but also the potential benefits of migration for the migrants themselves, the community of origin, and the communities of transit and destination (Gemenne and Blocher 2017). Migration can, under the right conditions, improve migrants' physical and environmental security as well as their socio-economic conditions (through improved access to jobs and a better income, for instance), as well as those of their households and communities of origin, and contribute to the economies and social fabric of destination areas. Migrants' contributions to societies of origin and destination cannot, however, be reduced to their economic value.

Within this more impact-focused element of migration-as-adaptation, empirical work mainly targets the effects of migration on households and communities of origin. Internal and international migrants may contribute to varying extents to greater resilience and adaptive capacity via social and financial remittances. Social remittances through the transfer of beliefs, values, knowledge, and skills gained through migration can bolster in situ adaptation efforts, for example, providing new or updated technological expertise in agriculture (Levitt 1998; Scheffran et al. 2012). Social remittances, however, are seldom empirically targeted: the vast majority of theoretical and empirical literature focuses on financial remittances as they may support the resilience of households and communities of origin. With money and gifts in-kind provided by migrants, households may reduce poverty levels, be able to decrease their dependence on natural resource-based livelihoods, diversify their livelihood strategies, build more disaster-resilient homes, and invest in new technologies such as irrigation systems, and so on (Ionesco et al. 2017). For instance, remittances can be used by agricultural households to overcome the loss of income that may arise from drought and subsequent crop failure (Massey et al. 1993). At the meso-level, diaspora members (internal and international) may invest in development projects, infrastructure or disaster risk reduction, or create spill-over effects through household remittances' stimulation of the local economy.

However, these beneficial outcomes are far from universal or inexorable. In many ways, therefore, the migration-as-adaptation discourse puts an environmental 'twist' on the long-held migration and development debate regarding the impacts of transnational practices (De Haas 2007). The extent to which these remittances are beneficial beyond the household-level or family network, for example, remains unclear. Even at the household-level, social and financial remittances, or any transnational or translocal practice for that matter, do not always occur. As they are most 
classically motivated by family responsibilities, a lack of close relatives or fraught relations can diminish or altogether cease transnational practices (Zickgraf 2014). Additionally, migration often entails important socio-economic costs for both migrant and non-migrant populations in the short and long term, depending on a set of preconditions at the micro-, meso-, and macro-levels, such as the policy environment and population dynamics as well as pre-existing structural vulnerabilities. Migrants' individual circumstances and situations in their transit or destination country affect their ability to take part in transnational activities (e.g., remittances, solidarity projects, visits to their home country) and, ultimately, to contribute to boosting the socio-economic and environmental resilience of their household or community of origin (Adger et al. 2018; Scheffran et al. 2012).

\subsubsection{Results}

\subsubsection{Perceptions of Environmental Changes in Morocco}

In order to understand the impacts of environmental changes in Morocco and the respondents' communities of origin on both their own migration motivations and their subsequent transnational practices, this section examines firstly respondents' perceptions of changes and hazards, such as drought. Perceptions of environmental changes, including climate change, at both the individual and community level, vary greatly according to a range of socio-demographic and cultural characteristics, including one's educational attainment, age, belief system, or direct experience with such changes and how they may or may not impact their livelihoods (Henry et al. 2003, 2004; Van der Land and Hummel 2013; cf. Chap. 5). Both objective and subjective elements shape how environmental disruptions are perceived and described by individuals and communities. Recent research has shown that although the subjective perceptions of environmental changes do not necessarily align with objective meteorological data, they are key determinants of the migration decisionmaking process (De Longueville et al. 2020). Furthermore, one's propensity to act towards reducing climate and disaster risk as well as to adapt to both ongoing and future changes may derive from their perception of environmental changes and risks and, in some cases, from biases that tend to normalize these phenomena or recognize them as external forces beyond one's control, e.g., acts of God (Schmuck 2000; Holmgaard 2019; Gianisa and Le De 2018).

Despite Morocco's ranking as second-best performing country in the 2019 Climate Change Performance Index (CCPI) globally, and its first position within the African continent and the Middle East and North Africa (MENA) region (Germanwatch 2018), according to a recent study, 39\% of Moroccans had never heard of climate change (Afrobarometer 2019). The composition of our sample, predominantly educated, employed Moroccan migrants coming from the broad middle-class and non-agricultural backgrounds, appears to be in line with the findings of this study: respondents with higher educational attainment (particularly 
those with tertiary education) exhibited more awareness particularly around the impacts of climate change. For example, Amina (27) and Cherifa (26), two Master students from Tetouan, became aware of climate change issues at school in Morocco.

Demonstrating the importance of livelihood as well, Saida (30, Sidi Slimane), who was concluding her PhD studies at the time of the interview and working as a freelance journalist, reported having been directly involved in raising awareness about environmental changes (after having left Morocco) through writing articles on water shortages affecting rural Morocco. However, not all respondents had been educated on environmental issues before their departure. For example, Rachida (39, Tangier) explained having only heard of the notion of 'climate change' once she arrived in Belgium.

The interviewed Moroccan migrants living in Belgium were all aware of environmental change in Morocco, either prior to their migration or after arrival in Belgium. Nonetheless, the sample demonstrated varying perceptions of environmental changes and stress. The primary environmental hazard cited was erratic precipitation, although this varied according to region of origin, where flooding, deforestation, and pollution were also reported. These disruptions were generally perceived to have significant impacts on rural and poor households, confirming previous findings according to which environmental changes are especially felt by people working in the agricultural sector (particularly subsistence farming) and who depend on the natural environment to secure their livelihoods (Ellis 2003; Wodon et al. 2014). Indeed, in natural resource-based economies (e.g., smallholder farming, fishing, breeding), livelihoods rely on practices and conditions that are highly dependent upon climate variability (e.g., rain-based irrigation, cattle grazing, availability of fish stocks). In case of weather-related disasters (e.g., drought), the income of farmers and fishers - and similarly, the livelihood of their communities and of their end consumers - are therefore directly and negatively impacted. For the majority of our sample, consisting of urban non-agricultural households, the effects were primarily felt through food prices rather than direct impacts on their livelihoods. In particular, decreased rainfall was perceived to negatively impact the average Moroccan consumer:

Samir (53, Tangier): Up to this day, Moroccans still buy fruits or vegetables directly, locally [produced], even though supermarkets are opening. Therefore, they feel it directly in their wallets. When it rains, they are extremely happy of course, because they tell themselves: There you go, food is going to be affordable! For them, when it rains, that means there is nice weather!

In addition to the direct economic impacts of decreased rainfall and crop failures on the purchasing power of Moroccan consumers, other associated impacts included diseases and water shortages (impacting drinking water). Rainfall (or the lack thereof) was therefore often used to illustrate environmental changes, being a tangible and visible phenomenon that was presented as being central to Moroccans' daily lives. For instance, Marouane (49, Larache) stressed that people must visualize and live these changes to understand them. 
Environmental changes materialize through objective and observable elements, such as changing precipitation patterns. Furthermore, previous research has shown that environmental factors are mainly perceived to influence people's lives and livelihoods through associated social and economic impacts (Moyo et al. 2012; TGOFS 2011; Borderon et al. 2018), such as food insecurity, inflation of commodity prices, or declining rural wages. Assessing the human dimensions of environmental changes therefore requires acknowledging the propensity of such changes to interact with a multiplicity of sectors and policies that communities and policymakers would not instinctively link to human mobility, but rather to wider issues of poverty reduction or sustainable development.

Although most respondents were aware of environmental issues and impacts, the majority and their families had not been directly affected by these disruptions prior to their migration outside of the stated impacts on food prices. Three exceptions include Rachida, Cherifa, and Nabil, all of whom had been affected by water shortages in Tangier, Tetouan and Berkane respectively. Rachida (39, Tangier) experienced drought-related water cuts before arriving in Belgium in 2002, and Cherifa (26, Tetouan), recalled water shortages that impacted both agricultural activities and the supply of drinking water in Tetouan, especially in 2016; during one month, she and her family had to fill water containers at set hours. Nabil (50), originally from Berkane (an important farming region in Morocco), reflected on how drought periods had affected his house-painting business, explaining how his wealthy clients - usually large-scale farmers or land owners - were less inclined to hire in such periods as they were incurring economic losses. Explaining that the wheels of the economy would stop spinning during times of drought, he recalled a particularly severe drought event in the late 1980s. Although he was one of the few to be directly affected by rainfall shortages, he did not feel that these problems still posed a challenge in Berkane.

In fact, several respondents, including Nabil (50, Berkane), saw such droughtrelated impacts as a thing of the past, owing primarily to state-led efforts towards ensuring the sustainability of the agricultural sector - such as the Plan Maroc Vert (Green Morocco Plan, cf. Chap. 3). Launched in April 2008 by King Mohamed VI, the Green Morocco Plan officially seeks to develop and modernize the agricultural sector through private investments, but also to tackle food insecurity and promote more inclusive agricultural systems (Ministry of Agriculture, Sea Fishing, Rural Development, Water and Forests 2014):

Nabil: Now, through the Green Morocco Plan, the government has introduced many provisions, invested a lot of money, and is doing a lot to help farmers. For instance, if you want to buy a tractor, the State will subsidize up to 60 per cent of the purchase. In fact, we pay it over 3 or 4 years. You want to dig a well, it's the same thing. You want to install a drip irrigation system... the State intervenes.

In fact, other respondents, such as Latif (52, Tangier), similarly implied that environmental issues in Morocco had largely been solved via government intervention: 
Latif: Back home, it's fine, it's green everywhere, you see ... flowers everywhere, you see? Morocco is humid. And thanks to Hassan II [King of Morocco from 1961 to 1999], he put a lot of dams [Sic].

As shown by these examples, positive perceptions about the environment can be linked to a naturally favourable climate, but also thanks to man-made, public efforts such as construction of infrastructure that aims to better manage natural resources. Farouk (51, Tangier) also felt that technological innovations and increased means had contributed to improving the current agricultural situation, citing political issues and unemployment as the two main issues currently facing the country:

Farouk: Nowadays, we don't talk about it [drought-related problems], now that the majority of people are digging wells, technology has evolved, people are living relatively better ... There was a time when it wasn't the case you know ... Now, there are dams, big cities. Tangier is a very big city. They have opened harbours ... Morocco has evolved a lot, in terms of infrastructure... There's everything you need.

Respondents with prior internal migration experience $(n=8)$ compared environmental contexts and state-led interventions across cities with mixed results, underlining the importance of local-level environmental perceptions (cf. Chap. 5). For instance, Hamid (42, Tinghir), who had lived in Tinghir, Tetouan, Tangier, and Agadir, was quite positive about efforts undertaken by the government in Tangier (where he had lived until 2007), suggesting that the city's cleanliness and respect for its natural environment - which he contrasted with Casablanca, Tetouan and Agadir - could be explained by the government's desire to preserve the city's position as a prime gateway to Europe:

Hamid: Back home honestly, in terms of the environment, Morocco was really conscious about this issue. The State, especially, gives a lot of importance to the environment, the forests surrounding Tangier have always been preserved. I have never seen someone cutting trees, there's incredible control over there. I don't know if that's [because] Tangier is closer to Europe and that it's the door to Morocco, that the State has been really controlling the region and keeping it 100 per cent natural ... In Tangier, there are no slums, it's very rare. In Casablanca, there are big slums and for the environment, for the quality of life, it's hell!

In addition, some respondents drew attention to the consequences of certain populations being isolated from the public eye and their ensuing limited capacity to cope with disasters. For instance, Cherifa (26, Tetouan) was aware of the adverse impacts of excess rainfall in different parts of the country, pointing to the differentiated capacities of authorities and populations to cope with disaster risk depending on the remoteness of a given city and of the visibility of a flood event. Furthermore, Samir (53, Tangier), drew a connection between drought, water scarcity, and social unrest by recalling riots that broke out in Al Hoceima (at the northern edge of the Rif mountains) in 2016 following the death of a fishmonger whose merchandise had been confiscated by the police. The social unrest which ensued and came to be known as Hirak Rif, or the Rif Movement, took place in a context where reduced rainfall and low crop yields resulted in mounting inflation. According to Samir, this could be further explained by the fact that locals had been facing recurrent water cuts which, despite being aimed at reducing water consumption and avoiding shortages, 
were in reality organized in an unfair way by local authorities. As a result, access to water became an object of social mobilization. These observations are consistent with the Rif region's long tradition of social unrest (Wolf 2018).

While some respondents applauded local and state-led interventions in certain cities, many noted the persistent need for greater awareness-raising amongst the Moroccan civilian population. Marouane (49), who worked as a teacher in Larache (approximately $100 \mathrm{kms}$ south of Tangier) and who currently works as a social worker in Belgium, explained the general population's lack of concern for environmental issues by a lack of investment in human capital. He also alluded to the corruption of political elites, whom he accused of over-exploiting natural resources in an unregulated and globalized economic context and of not prioritizing the environment, observing the following:

\begin{abstract}
Marouane: We don't focus on citizens' awareness in order for them to take care of the environment. That's the problem. Morocco's problem is not simply linked [to] global warming in general, it is also linked to the behaviour of citizens themselves, of societies, companies, and of the State, who doesn't do anything about it ... The media doesn't talk about it much, schools don't talk about it much. It's true that every summer, we organise awareness campaigns to keep the beaches clean and everything, but those remain limited actions.
\end{abstract}

Samir (53, Tangier) had similar views on the need to educate people, giving the example of plastic pollution, which he called a calamity and reflected on his youth when beaches were much cleaner:

Samir: A problem that also becomes clear when you go to the shops, for instance, which is a reflex many merchants have, is that you buy a pack of sugar, they put it in a plastic bag. You buy matches, they put them in a plastic bag ... It's systematic. People should re-educate themselves about this. But people are not disciplined. And ... there was no real awareness.

Samir further explained that the state had started taking measures a few years back to address plastic pollution in order to protect the tourism industry as well as to promote changes in behaviour with regards to plastic use and water waste.

Perceptions of environmental changes in Morocco, including climate change, varied greatly within our sample. Although some respondents were confident that environmental issues like erratic rainfall had been resolved by the Moroccan state, others noted the considerable differences from one city or rural area to another, citing the variation between environmental hazards (floods, drought, deforestation), livelihood dependence, government responses, and behaviours of local populations.

\title{
8.1.1.2 Environmental Changes and the Migration Decision
}

As demonstrated in this first section, Moroccan migrants from our sample demonstrated significant, if heterogeneous, awareness of environmental disruptions affecting their home country and of their associated socio-economic and political impacts. Yet, migrants' appreciation of environmental changes (including of their causes, 
consequences, and potential solutions) in their home country does not automatically mean that these changes affected their own migration journey. This section, therefore, explores respondents' migration motivations, highlighting the different factors that have played a role in their migration aspirations and decisions. It investigates if, and how, environmental factors have impacted them (or their household of origin) to assess whether environmental changes can be considered a catalyst of migration for our respondents.

While our sample was generally aware of environmental changes affecting their areas of origin and Morocco in general, none of the respondents, in fact, identified adverse weather shocks or gradual changes as a major reason for their own migration. However, in line with previous research (Nguyen and Wodon 2014; Wodon et al. 2014), respondents acknowledged that insufficient agricultural revenue (linked to drought and other weather shocks) may affect the livelihoods of agriculturedependent households and lead to - mainly internal - migration patterns. This categorisation of environmental-related migration was often perceived to be a relatively new phenomenon, which contrasts with previous labour migration trends:

Farid (60, Tangier): I think that it's only now, it's only been a few years since we've started talking about people leaving their country because of droughts or other climatic problems or other issues such as politics ... I had never heard of this before.

Middle and upper-middle class urban respondents cited the rural plights of the poor, especially those depending on natural-resource livelihoods, whose vulnerability led to internal and international migration. These testimonies stressed the underlying inequalities between households that are socio-economically advantaged and those with fewer resources and connections and which can contribute to shaping migration aspirations (cf. Chap. 6). One participant cited the risks incurred by populations in particularly dry and poor mountainous regions such as in Azilal (in the Mid-Atlas mountains), recognizing that neglected inhabitants were the most likely to cross the Mediterranean: 'That's when people take risks and cross the sea to go to Europe, actually' (Nabil, 50, Berkane). This observation is confirmed in a study showing that Moroccan households from the Tadla Azilal region were the second most likely to have one household member who had migrated to Europe (19\% of households) after those from the Oriental (Eastern) region (23\%) in 2009/ 2010 (OECD 2017).

Farida (46, Tangier) recalled similar issues in the mountains of Irfan, where she worked as a teacher and where nomadic populations were facing hardship due to the lack of firewood in winter. As the government had banned cutting trees for timber, locals would do so at night, illegally rather than buy the wood sold by the state, stressing the fact that destitution, adding on to the corruption of local authorities, may further reduce the environmental resilience of the most remote and vulnerable populations. Farida explained that some would migrate to small towns nearby such as Ifran, Azru, Imouzzer Kandar or larger cities such as Fez or Meknes, but that rural-rural immigration was favoured by these populations because it was more affordable. This further supports the idea according to which mobility in the context of environmental change is likely to apply to shorter distances, owing to the 
importance of capital necessary to migrate long distances and internationally (Piguet and Lackzo 2014; Van Praag and Timmerman 2019).

Kamel (40), recalled water shortages related to harmful irrigation practices in his hometown of Kaa Asrass, where water from rivers was captured by cannabis plantations in nearby villages. This would eventually cause the rivers to dry up and, in turn, force non-cannabis farmers to rely on unpredictable rainfall to irrigate their fields. He further linked the culture of cannabis to rural-urban migration, with cannabis farmers and salesmen moving to the city and living ostentatious lifestyles, while the state turned a blind eye. Saida (30, Sidi Slimane), who identified as upper middle class, was well-aware of the contrasting vulnerability of poorer populations, mentioning high flood risks in the nearby river of Sidi Slimane suburbs, where small villages were affected by recurring floods. She gave the example of Zagora, in southeastern Morocco, where local populations had staged a protest against the authorities due to shortages of drinking water: 'For these people, it's absolutely normal: there's no water, therefore they will migrate' (Saida, 30, Sidi Slimane).

In its second national communication to the United Nations Framework Convention on Climate Change (UNFCCC), the Moroccan government explicitly drew a link between increasing rural-urban migration between Central Morocco to the Atlantic coast and drought periods which are increasing in intensity and frequency (Government of Morocco 2010). This was confirmed by Farouk (51, Tangier), according to whom the interlinkages between drought, agriculture and both internal and international migration (particularly in the Rif region) were also clear. Regarding the internal movement of his family from rural Morocco to Tangier (prior to his birth and his move to Belgium at a very young age), and based on insights from older people, he comments: 'Back there, there was drought and farming was made impossible ... And it wasn't just my father. a large part of the Rif's population immigrated to cities, and others went further away, leaving to Europe' (Farouk, 51, Tangier). As demonstrated in this excerpt, migration historically acted as a livelihood diversification strategy for many Riffians (which is in line with new economics of labour migration, cf. Chap. 2). As Farouk's family could not live from farming anymore as there was no food to feed the cattle, immigration was used as a coping mechanism.

Most respondents reported having not been personally impacted by the effects of environmental changes and did not consider them to have affected their own migration aspirations and trajectories. Households that are less dependent on natural resources to secure their livelihoods are less likely to suffer from the impacts of environmental change due to lower sensitivity and a stronger coping capacity. For instance, although Saida (30, Sidi Slimane), acknowledged that Morocco was a country that based its economy on agriculture and thus relied on rain and the environment, her family had not been affected by the lack of rain. Indeed, her father was working in the clothing retail and not food products, although the family did own a few pieces of land on which they cultivated orange trees and wheat respectively. While the first lot was never impacted by the lack of rain as it benefited from drip irrigation, the second relied on rainfall. Saida further nuanced the perceived impact of the lack of rain as her household did not rely on these agricultural products 
for their subsistence but could easily buy their own wheat (at higher prices) if necessary.

Instead of suggesting the existence of direct linkages between environmental changes and migration between Morocco and Belgium, the composition of our sample aligns with previous findings demonstrating that Moroccan migrants are still mainly migrating to Europe to reunite with family members, especially through marriage migration, in addition to emerging forms of migration that include students or undocumented migrants (Timmerman et al. 2017; cf. Chap. 3). In fact, the majority of participants $(n=10)$ reported having migrated to Belgium due to family reasons while a minority reported having moved for work or study reasons. In some of the family reunification cases, the head of the household (here, the father) had initially migrated to Belgium for work and thus to improve his family's economic situation. For instance, Samir (53, Tangier) and his mother, joined the head of the household (their father and husband respectively) in Belgium, where he had moved in 1966 in the framework of the Belgian-Moroccan bilateral work agreements. With the exception of these family reunification cases consisting of respondents joining the head of their household in Belgium at a very young age, other cases consisted of spouses reuniting in Europe in order to live together. Some participants also reflected on their move as a way of starting over (e.g., after the death of a husband, a traumatic incident) or, simply, to start a new life. For Chafiq (63, rural outskirts of Tangier), who reported having migrated to Belgium in the 1970s for work, the initial goal was to improve his family's circumstances and access new economic opportunities through integrating an urban setting, as he was working in the farming sector and was facing a decline in agricultural activity, including a reduction in arable and cattle grazing land. Furthermore, given that multi-causality is a fundamental characteristic of human mobility, a mix of migration drivers, evolving over time and space, could be observed within our sample, although environmental disruptions were never explicitly identified by the respondents as a direct cause for their (internal and international) migration.

As we have demonstrated in this section, the Moroccan diaspora's comprehension of environmental disruptions in their home country does not imply that these changes will have had a decisive impact on their decision to migrate (nor that they are unaware of them, as demonstrated in the previous section). In the case of our sample, other elements, such as pre-existing migration networks, historical migration trends, and cultures of migration (cf. Chap. 7) appeared to play a more salient role in respondents' move to Belgium. This is in line with other findings from this book which suggest that the role played by environmental factors in shaping respondents' migration aspirations and trajectories had largely been overshadowed by that of social and economic factors and opportunities (cf. Chap. 6). Nonetheless, environmental changes in Morocco could have made migration more attractive for (young) people, who want to increase their future opportunities. On the one hand, this supports empirical studies that suggest most migration induced by environmental changes remains within national boundaries. On the other hand, this demonstrates that when climate change occurs in 'cultures of migration', where long histories of migration exist, its impacts on international outflows are not always readily apparent. 
This lack of perceived relevance of environmental factors in the migration decision may, in turn, suggest that transnational practices of diaspora members will not be directly aimed at, or linked to, environmental resilience efforts.

\subsubsection{Transnational Practices and Environmental Resilience}

Considering the awareness of environmental degradation in Morocco, but the limited or non-existent role of environmental change as a driver of migration to Belgium, this section questions whether perceptions of environmental matters affect transnational practices, and whether those practices improve the environmental resilience of their households and communities of origin in Morocco. We argue that such practices rely on the extent to which environmental changes are perceived to have a direct impact on the migrants themselves or their family in Morocco.

Transnational practices of Moroccan migrants cannot be understood without considering pre-existing cultures of migration, as well as the relationship between the Moroccan government and its diaspora. Since the late 1980s, the Moroccan government has encouraged the transfer of remittances to Morocco as a development and poverty reduction tool (Bouoiyour 2008; Dadush 2015; cf. Chap. 3). The latest World Bank report on migration and remittances ranked Morocco second (after Egypt) amongst countries that had received the largest amount of remittances in the MENA region; Morocco received 7.4 billion US dollars from its diaspora in 2018, amounting to $6.2 \%$ of GDP (The World Bank 2019). Similarly, visits of Moroccan diaspora members living in Europe have reached such significance that they have been institutionalized through governmental initiatives such as the annual transport coordination Operation Marhaba, which were launched to facilitate the travels of Moroccans Residing Abroad (Marocains Résidant à l'Étranger) who decide to undertake the journey (by boat) between selected Spanish, French, and Italian ports and Morocco (Tangier, Nador, Al Hoceima) between 5 June and 15 September (Opération Marhaba 2019).

In line with other research, three broad categories of transnational practices apply to the Moroccan diaspora in Belgium, namely: mobility (regular visits between Belgium and Morocco), communication activities, and material transfers (Zickgraf 2014). Regardless of the heterogeneity of their (perceived) levels of socio-economic integration into Belgian society and satisfaction with their current lives, the overwhelming majority of respondents had maintained strong ties with their community of origin, whether through regular contacts (maintained through telecommunications or physical visits to Morocco), financial remittances (including gifts in-kind and other material exchanges), and the transmission of information and ideas (social remittances).

While the large majority of the sample had close family members or members of their household of origin in Morocco, such as parents and siblings, the remaining respondents had, at the minimum, extended family, family-in-law, or friends in Morocco. The contacts with people living in Morocco were principally maintained 
through telecommunications (by phone but also through WhatsApp or Skype, for instance) several times a month, but also through regular visits to Morocco, usually once a year, during the summer holidays. These contacts were made easier through the wider availability of communication tools such as the internet and advantageous costs for telecommunications between Belgium and Morocco. For most of our respondents, these regular interactions with their community of origin, both digital and physical, were perceived as crucial to staying updated with the situation of relatives back home, communicating about special events, but also for having firsthand accounts of the situation in the country of origin - justifying and leading to the transfer of financial and non-financial remittances in most cases. As such, financial remittances and other material exchanges can be seen as an extension of this aspiration to stay close to one's family or community of origin, exposing symbolic motivations for material and financial transfer (Zickgraf 2014; McKay 2007).

The overwhelming majority of respondents in our sample did (or used to) send back financial remittances, which they justified by family solidarity or religious reasons, and which, in some cases, were described as a mission or a permanent or sacred obligation. As suggested by Samir (53, Tangier), migrants may feel a certain duty to bring material gifts when going back home: 'For my father, it was out of the question to go [to Morocco] empty-handed. If there were no gifts, we didn't go'. Financial and gifts in-kind were therefore grounded into philosophical, moral, and religious principles. As expressed by Marouane (49, Larache) and others, giving and helping were indeed seen as leading to potential rewards, whether by God or individuals:

Marouane: You know... Whether it's my family back there [in Morocco] or back here [in Belgium], or anyone else in any kind of situation, it's the same to me. What's important, when you can afford it, is to help when you can help. It's important to help because we only reap what we sow. If we help others and require help ourselves at some point, we will be helped too. That goes without saying, it's my philosophy.

Financial remittances were, therefore, mainly seen as self-evident and largely expected to cover the daily expenses of the household back home (e.g., food, housing, clothing, electricity, health, education), or made occasionally, in the case of health issues or life events (births, deaths), for instance. Another key moment of solidarity appeared to be religious holidays such as the Festival of the Sacrifice (Eidel-Adha) where respondents reported sending money to buy the sheep and food for the feast. However, although financial remittances could be perceived as a risk mitigation strategy and as a way to remain close to one's community of origin, respondents never identified them specifically as a way to contribute to the environmental resilience of their households and communities of origin. This can partly be explained by the fact that, as demonstrated above, they did not perceive environmental changes to have affected them (or their household) directly, but also that respondents did not interfere with how the money was spent. As Nabil (50, Berkane) explained: 'Mothers are sacred, as we say. I have never asked mine what she does with the money!' As such, it appears that remittances sent by and for those 
unaffected by environmental changes will only be peripherally linked to adaptation to environmental changes and resilience.

Therefore, there is little evidence so far to suggest that Moroccans in Belgium prioritize environment as a key challenge and, therefore, as a potential object of their transnational practices: assuming that remittances and other practices will be, or are, an adaptive tool neglects this important point. They may, however, have a direct impact on the income structure of the household and improve its capacity to cope with surges in commodity prices that are linked to drought phenomena. Moreover, it is possible to recognize the potential spillover effect of financial remittances on environmental resilience by improving the socio-economic conditions at the household level and therefore increasing coping and adaptive capacities in response to potential environmental shocks and stressors.

\subsection{Conclusions}

Findings from this chapter demonstrate that Belgian first-generation migrants from Morocco are at least to some extent attuned to the impacts of environmental change as well as historical experiences of environmental degradation in their country and communities of origin. As mentioned above, this may be facilitated by the relatively high average level of educational attainment across our sample. Nevertheless, opinions on whether environmental change is currently a major challenge facing Moroccan populations varied, with some believing it had largely been resolved by state intervention.

These perceptions of environmental changes at the meso level, however, did not drive the respondents to migrate to Belgium: migration to Belgium from the North African country continues to follow historical, more classic, pathways related to family reunification, education, and economic opportunities, amongst others. However, Moroccan migration to Belgium is dynamic and ever-evolving (Bousetta and Martiniello 2003; cf. Chap. 3), so this does not preclude a stronger, more discernible future impact of environmental change on Moroccan migration to Belgium, particularly when that migration occurs out of more rural, natural resource and agriculturedependent areas. Moreover, we acknowledge that our relatively small sample, leaning towards urban middle-class households, may have limited our ability to sufficiently capture current environmental drivers of nation-wide out-migration and domestic migration flows. These findings do support other empirical studies within and outside of the Moroccan context underscoring the primarily internal character of environmental migration (Wodon et al. 2014; McLeman and Gemenne 2018; IDMC 2020).

Additionally, the evidence from this chapter indicates that one must not assume that all people who leave areas affected by environmental changes do so because of those changes, particularly in places that have long histories and cultures of migration for various reasons (cf. Chaps. 5 and 6). Differentiated vulnerability within a given community results in variation in the extent to which climatic and 
environmental changes are directly 'felt' by households and individuals, and less sensitive households - e.g., those not dependent on agricultural livelihoods - which, in turn, affects their migration motivations as well as their subsequent transnational practices (Portes et al. 2002; Eckstein 2010). While validating the significance of transnational exchanges between Morocco and Belgium, including financial and social remittances, the motivation for engaging in these practices was primarily to maintain or reinforce familial relationships and obligations at a distance. Therefore, if households in the community of origin are not currently facing environmental duress or do not need to due to financial remittances sent from their relatives living abroad, it is unlikely that transnational practices will - intentionally - affect environmental resilience and adaptive capacity to climate change.

Nonetheless, even if migrants did not direct their transnational practices towards environmental resilience, it does not mean that environmental resilience and adaptive capacity cannot be 'collateral' by-products of long-established cultural and historical transnational relationships and practices, peripherally linked to adaptation and environmental resilience. Social and financial remittances, transferred through communication, mobility, or material exchange can still support long-term development and adaptation in communities of origin. They can do so through, for instance, improving general socio-economic well-being, decreasing disaster displacement risk through the construction of new homes, and stimulating local economies and other spill-over effects for the meso level (Levitt 1998; Kusunose and Rignall 2018; Nyberg Sørensen 2004). This, however, is not an inevitable outcome, as demonstrated by the breadth of scholarship on the migration-development nexus.

In conclusion, remittances from international migration, while in our case bringing benefits to the communities of origin, cannot be counted on as a primary adaptation strategy or means of building community-level environmental resilience, as expected by migration-as-adaptation discourses. Migrants, who individually or collectively are not directly affected by environmental changes, with the means and desire to engage in transnational practices outside of their family networks, would most likely have to be incentivized to support, financially or otherwise, communitybased projects targeting environmental resilience, sustainable development, or climate change mitigation or adaptation efforts, for example by reducing international transfer fees or adding a percentage to agricultural investments. Conversely, estrangement with one's community of origin may pose a barrier to action and prevent or inhibit such transnational practices. These ties may also fade or weaken, but dormant ties may reignite with subsequent generations (Zickgraf 2014).

The scientific community, the public, and policymakers should consider the adaptive potential of migration-as-adaptation and steer away from uniformly negative depictions of the relationship between migration and environmental changes. Even so, we caution against implicitly or explicitly considering these challenges as the 'migrant's burden'. Undoubtedly, social and financial remittances cannot substitute for adaptation interventions by governments and international organisations. 


\section{References}

Adger, W. N., de Campos, R. S., \& Mortreux, C. (2018). Mobility, displacement and migration, and their interactions with vulnerability and adaptation to environmental risks. In R. McLeman \& F. Gemenne (Eds.), Routledge handbook of environmental displacement and migration (pp. 29-41). London/New York: Routledge.

Afrobarometer. (2019). A slim majority of Moroccans are aware of climate change [in Arabic]. Press Release (14 February). Available at: http://afrobarometer.org/sites/default/files/pressrelease/Maroc/mor_r7_pr_climate_change_arabic.pdf. Accessed 29 Sept 2019.

Ayeb-Karlsson, S., Smith, C. D., \& Kniveton, D. (2018). A discursive review of the textual use of 'trapped' in environmental migration studies: The conceptual birth and troubled teenage years of trapped populations. Ambio, 47, 557-573.

Berriane, M., De Haas, H., \& Natter, K. (2015). Introduction: Revisiting Moroccan migration. The Journal of North African Studies, 20(4), 503-521.

Black, R., \& Collyer, M. (2014). Populations 'trapped' at times of crisis. Forced Migration Review, 45, 52-56.

Borderon, M., Sakdapolrak, P., Muttarak, R., Kebede, E., Pagogna, R., \& Sporer, E.. (2018). A systematic review of empirical evidence on migration influenced by environmental change in Africa. IIASA Working Paper. Laxenburg, Austria: WP-18-003. http://pure.iiasa.ac.at/id/eprint/ $15382 /$

Bouoiyour, J. (2008). Diaspora et dévelopement: Quelles interactions dans le cas marocain? Migrations Société, 6(120), 103-129.

Bousetta, H., \& Martiniello, M. (2003). Marocains de Belgique: du travailleur immigré au citoyen transnational. Hommes et Migrations, 1242, 94-106.

Brocklesby, M. A., \& Fisher, E. (2003). Community development in sustainable livelihoods approaches? An Introduction. Community Development Journal, 383, 185-198.

Collyer, M. (2007). In-between places: Trans-Saharan transit migrants in Morocco and the fragmented journey to Europe. Antipode, 34(4), 668-690.

Dadush, U. (2015). Diaspora, development and Morocco. Policy Paper (November). Rabat: OCP Policy Center.

De Haas, H. (2007). Migration and Development: A Theoretical Perspective (No. 29). Bielefeld: Center on Migration, Citizenship \& Development.

De Longueville, F., Ozer, P., Gemenne, F., Henry, S., Mertz, O., \& Nielsen, J. Ø. (2020). Comparing climate change perceptions and meteorological data in rural West Africa to improve the understanding of household decisions to migrate. Climatic Change, 1, 1-19.

Eckstein, S. (2010). Immigration, remittances, and transnational social capital formation: A Cuban case study. Ethnic and Racial Studies, 33(9), 1648-1667. https://doi.org/10.1080/ 01419871003725410 .

Ellis, F. (2003). A livelihoods approach to migration and poverty reduction. London: Department for International Development.

Gemenne, F. (2010). Migration, a possible adaptation strategy? Institut du développement durable et des relations internationales, $3,1-4$.

Gemenne, F. (2011). How they became the human face of climate change. In E. Piguet, A. Pécoud, \& P. De Guchteneire (Eds.), Migration and climate change. Cambridge: Cambridge University Press.

Gemenne, F. (2018). Qualitative research techniques: it's a case-studies world. In R. McLeman \& F. Gemenne (Eds.), Routledge handbook of environmental displacement and migration (pp. 117-124). Oxford: Routledge.

Gemenne, F., \& Blocher, J. (2017). How can migration serve adaptation to climate change? Challenges to fleshing out a policy ideal. The Geographical Journal, 183(4), 336-347.

Germanwatch. (2018). CCPI 2019 Country Results: Morocco 2019. https://www.climate-changeperformance-index.org/country/morocco-2019. Accessed 28 Sept 2019. 
Gianisa, A., \& Le De, L. (2018). The role of religious beliefs and practices in disaster: The case study of 2009 earthquake in Padang city, Indonesia. Disaster Prevention and Management, 27 (1), 74-86.

Government of Morocco. (2010). Seconde communication nationale à la Convention cadre des Nations Unies sur les changements climatiques (Avril 2010). www.abhatoo.net.ma/content/ download/20617/375478/version/1/file/seconde_communication_nationale_convention_ cadre_NU_chang_clim.pdf

Henry, S., Piché, V., Ouédraogo, D., \& Lambin, E. F. (2003). Modelling inter-provincial migration in Burkina Faso, West Africa: The role of socio-demographic and environmental factors. Applied Geography, 23(2-3), 115-136.

Henry, S., Schoumacker, B., \& Beauchemin, C. (2004). The impact of rainfall on the first out-migration: A multi-level event-history analysis in Burkina Faso. Population and Environment, 25(5), 423-460.

Holmgaard, S. B. (2019). The role of religion in local perceptions of disasters: The case of posttsunami religious and social change in Samoa. Environmental Hazards, 18(4), 311-325.

Hugo, G. (1996). Environmental concerns and international migration. International Migration Review., 30(1), 105-131.

IDMC. (2020). GRID 2020 - Global report on internal displacement. Geneva: The Internal Displacement Monitoring Centre.

Ionesco, D., Mokhnacheva, D., \& Gemenne, F. (2017). The atlas of environmental migration. London: Routledge.

Kniveton, D., Schmidt-Verkerk, K., Smith, C., \& Black, R. (2008). Climate change and migration: Improving methodologies to estimate flows (p. 33). Geneva: International Organisation for Migration. Migration Research Series.

Kumari Rigaud, K., de Sherbinin, A., Jones, B., Bergmann, J., Clement, V., Ober, K., Schewe, J., Adamo, S., McCusker, B., Heuser, S., \& Midgley, A. (2018). Groundswell: Preparing for internal climate migration. Washington, DC: The World Bank.

Kusunose, Y., \& Rignall, K. (2018). The long-term development impacts of international migration remittances for sending households: Evidence from Morocco. Migration and Development, 7 (3), 412-434. https://doi.org/10.1080/21632324.2018.1475383.

Levitt, P. (1998). Social remittances: Migration driven local-level forms of cultural diffusion. International Migration Review, 32(4), 926-948.

Martiniello, M., \& Rea, A. (2013). Une brève histoire de l'immigration en Belgique. Brussels: Fédération Wallonie-Bruxelles.

Massey, D. S., Arango, J., Hugo, G., Kouaouci, A., Pellegrino, A., \& Taylor, J. E. (1993). Theories of international migration: A review and appraisal. Population and Development Review, 19(3), 431-466.

McKay, D. (2007). 'Sending dollars shows feeling'. Emotions and economies in Filipino migration. Mobilities, 2(2), 175-194.

McLeman, R., \& Gemenne, F. (Eds.). (2018). Routledge handbook of environmental displacement and migration. London/New York: Routledge.

Ministry of Agriculture, Sea Fishing, Rural Development, Water and Forests. (2014). Maroc Vert: La Stratégie. www.agriculture.gov.ma/pages/la-strategie. Accessed 29 Sept 2019.

Morrissey, J. (2012). Rethinking the 'debate on environmental refugees': From 'maximalists and minimalists' to 'proponents and critics. Journal of Political Ecology, 19(1), 36-49.

Moyo, M., Mvumi, B. M., Kunzekwegueta, M., Mazvimavi, K., Crufurd, P., \& Dorward, P. (2012). Farmer perceptions of climate change and variability in semi-arid Zimbabwe in relation to climatology evidence. African Crop Science Journal, 20(2), 317-335.

Nguyen, M. C., \& Wodon, Q. (2014). Weather shocks, impacts and households' ability to recover in Morocco. In Q. Wodon, A. Liverani, G. Joseph, \& N. Bougnoux (Eds.), Climate change and migration. Evidence from the Middle East and North Africa (pp. 107-122). Washington, DC: The World Bank. 
Nyberg Sørensen, N. (2004). Migrant remittances as a development tool: The case of Morocco. Copenhagen: Danish Institute for Development Studies.

OECD. (2017). Le paysage des migrations en Europe. In Interactions entre politiques publiques, migrations et développement au Maroc (pp. 39-59). Paris: Editions OCDE. https://doi.org/10. 1787/9789264279193-6-fr.

Opération Marhaba. (2019). [online] http://operationmarhaba.mtpnet.gov.ma/. Accessed 30 Sept 2019.

Ouali, N. (Ed.). (2004). Trajectoires et dynamiques migratoires de l'immigration marocaine de Belgique. Louvain-la-Neuve: Academia-Bruylant.

Piguet, E., \& Lackzo, F. (Eds.). (2014). People on the move in a changing climate. The regional impact of environmental change on migration. Dordrecht: Springer.

Portes, A., Guarnizo, L. E., \& Haller, W. J. (2002). Transnational entrepreneurs: An alternative form of immigrant economic adaptation. American Sociological Review, 67(2), 278-298. https://doi.org/10.2307/3088896.

Scheffran, J., Marmer, E., \& Sow, P. (2012). Migration as a contribution to resilience and innovation in climate adaptation: Social networks and co-development in Northwest Africa. Applied Geography, 33, 119-127.

Schmuck, H. (2000). An act of Allah': Religious explanations for floods in Bangladesh as survival strategy. International Journal of Mass Emergencies and Disasters, 18(1), 85-95.

Stark, O. (2005). Comment on 'Migration and income in source communities: A new economics of migration perspective from China. Economic Development and Cultural Change, 53(4), 983-986.

Stark, O., \& Bloom, D. E. (1985). The new economics of labour migration. The American Economic Review, 75(2), 173-178.

Suhrke, A. (1993). Pressure points: Environmental degradation, migration and conflict. Cambridge, MA: American Academy of Art and Science.

Taylor, J. E. (1999). The new economics of labour migration and the role of remittances in the migration process. International Migration, 37(1), 63-88.

The Government Office for Science (TGOFS). (2011). Foresight: Migration and global environmental change future challenges and opportunities. London: The Government Office for Science.

The World Bank. (2019, April). Migration and remittances. Recent developments and outlook (Migration and Development Brief No. 31). Washington, DC: The World Bank.

Timmerman, C., Fadil, N., Goddeeris, I., Clycq, N., \& Ettourki, K. (2017). Introduction. In C. Timmerman, N. Fadil, I. Goddeeris, N. Clycq, \& K. Ettourki (Eds.), Moroccan migration in Belgium: More than 50 years of settlement (pp. 9-20). Leuven: Leuven University Press. https://doi.org/10.2307/j.ctt21c4s72.

Van der Land, V., \& Hummel, D. (2013). Vulnerability and the role of education in environmentally induced migration in Mali and Senegal. Ecology and Society, 18(4).

Van Praag, L., \& Timmerman, C. (2019). Environmental migration and displacement: A new theoretical framework for the study of migration aspirations in response to environmental changes. Environmental Sociology, 5(4), 352-361. https://doi.org/10.1080/23251042.2019. 161303.

Wodon, Q., Burger, N., Grant, A., Joseph, G., Liverani, A., \& Akacheva, O. (2014). Climate change, extreme weather events and migration: Review of the literature for five Arab countries. In E. Piguet \& F. Lackzo (Eds.), People on the move in a changing climate. The regional impact of environmental change on migration (pp. 111-134). Dordrecht: Springer.

Wolf, A. (2018). Morocco's Hirak movement and legacies of social unrest in the Rif. The Journal of North African Studies, 24(1), 1-6. 
Young, L. (1985). A general assessment of the environmental impact of refugees in Somalia with attention to the refugee agricultural programme. Disasters, 9(5), 122-133.

Zickgraf, C. (2014). Family from afar: Moroccan migration, family practices and the transnational social space. Unpublished doctoral dissertation, Université de Liège, Liège, Belgium.

Zickgraf, C. (2018). Immobility. In R. McLeman \& F. Gemenne (Eds.), Routledge handbook of environmental displacement and migration (pp. 71-84). London/New York: Routledge.

Open Access This chapter is licensed under the terms of the Creative Commons Attribution 4.0 International License (http://creativecommons.org/licenses/by/4.0/), which permits use, sharing, adaptation, distribution and reproduction in any medium or format, as long as you give appropriate credit to the original author(s) and the source, provide a link to the Creative Commons license and indicate if changes were made.

The images or other third party material in this chapter are included in the chapter's Creative Commons license, unless indicated otherwise in a credit line to the material. If material is not included in the chapter's Creative Commons license and your intended use is not permitted by statutory regulation or exceeds the permitted use, you will need to obtain permission directly from the copyright holder. 